\title{
Electronic and structural properties of doped amorphous and nanocrystalline silicon deposited at low substrate temperatures by radio-frequency plasma-enhanced chemical vapor deposition
}

\author{
P. Alpuim ${ }^{*}{ }^{\text {a) }}$ V. Chu, and J. P. Conde ${ }^{\text {b) }}$ \\ a) Instituto de Engenharia de Sistemas e Computadores - \\ Microssistemas e Nanotecnologias (INESC-MN) \\ Rua Alves Redol, 9, 1000-029 Lisboa, Portugal \\ ${ }^{b)}$ Department of Materials Engineering, Instituto Superior Técnico, \\ 1049-001 Lisboa, Portugal
}

PACS: 73.61.Jc, 73.63.Bd, 81.05.Gc, 81.07Bc, 81.15Gh, 71.55Cn, 68.55.Ln 


\section{Abstract}

The gas phase doping of hydrogenated amorphous silicon and hydrogenated nanocrystalline silicon thin films deposited on glass and on plastic (polyethylene terephthalate) substrates is reported. Two substrate temperatures were used during deposition: $25^{\circ} \mathrm{C}$ and $100{ }^{\circ} \mathrm{C}$. Films were deposited by radio-frequency plasmaenhanced chemical vapor deposition using phosphine or diborane for $\mathrm{n}$ or $\mathrm{p}$-type doping, respectively. Similar electronic and structural properties are obtained for the doped films deposited on either substrate. Hydrogen dilution of silane is used to improve the electronic and structural properties of the amorphous films and to obtain nanocrystalline films. The most conductive amorphous films have n-type dark conductivity at room temperature $\sim 10^{-3} \Omega^{-1} \mathrm{~cm}^{-1}$ and $\sim 10^{-5} \Omega^{-1} \mathrm{~cm}^{-1}$ when deposited at $100{ }^{\circ} \mathrm{C}$ and $25^{\circ} \mathrm{C}$, respectively, or p-type room temperature dark conductivity $\sim 10^{-7}$ $\Omega^{-1} \mathrm{~cm}^{-1}$ at both substrate temperatures. The most conductive nanocrystalline films deposited at $100{ }^{\circ} \mathrm{C}$ have n-type and p-type dark conductivity at room temperature above $10^{-2} \Omega^{-1} \mathrm{~cm}^{-1}$ while nanocrystalline films deposited at $25^{\circ} \mathrm{C}$ only have p-type conductivity higher than $10^{-2} \Omega^{-1} \mathrm{~cm}^{-1}$ at room temperature. Isochronal annealing at temperatures up to $300{ }^{\circ} \mathrm{C}$ showed that the dopants are fully activated at the deposition temperature in doped nanocrystalline samples and that they are only partially activated in amorphous films deposited at low substrate temperatures. 


\section{Introduction}

A growing demand for functional devices and electronic circuits on flexible, lightweight and inexpensive substrates has created the need to study the growth and optimize the properties of amorphous and nanocrystalline silicon deposited at low substrate temperatures on plastic substrates. ${ }^{1,2,3,4,5}$ Recently, low-temperature amorphous silicon thin film transistors (TFTs) fabricated on glass were reported, using deposition temperatures of $150{ }^{\circ} \mathrm{C}$ [ref.6] and $125^{\circ} \mathrm{C}$ [ref.7], and on plastic, at $125{ }^{\circ} \mathrm{C}$ on polycarbonate, ${ }^{2}$ at $150{ }^{\circ} \mathrm{C}$ on polyimide, ${ }^{3}$ and at $100{ }^{\circ} \mathrm{C}$ and $110{ }^{\circ} \mathrm{C}$ on polyethylene terephthalate. ${ }^{4,5}$ The layers for the devices were deposited by radiofrequency plasma-enhanced chemical vapor deposition (RF) except for the device of ref.7, where reactive magnetron sputtering was used.

Radio frequency plasma enhanced chemical vapor deposition, rf-PECVD, is currently the industry-standard deposition technique for a-Si:H thin film growth. This technique owes its importance to the high electronic quality and homogeneous properties of the films deposited over large areas. ${ }^{8}$ However, the usual substrate temperature for optimized a-Si:H films deposited with rf-PECVD is around 200-250 ${ }^{\circ} \mathrm{C}$. To apply this deposition technique to inexpensive plastic requires the reduction of the film deposition temperature to below $150{ }^{\circ} \mathrm{C}$ while still obtaining acceptable electronic properties in the film. Efficient doping at low temperatures is critical to the fabrication of a semiconductor device on plastic. A highly conductive doped layer is necessary in devices such as TFTs and Schottky diodes to provide a low resistance Ohmic contact. Insufficient doping in these devices results in a series resistance in the 
on-state of the device. In a-Si:H-based p-i-n diodes, the different positions of the Fermi level of the $\mathrm{p}$ and $\mathrm{n}$ layers create an internal field across the i-layer which determines the built-in voltage.

Doping of a-Si:H was first demonstrated by Spear and Lecomber. ${ }^{9}$ For optimized deposition conditions $\left(T_{\text {sub }} \geq 200{ }^{\circ} \mathrm{C}\right)$, room temperature dark conductivity, $\sigma_{\mathrm{d}}$, are generally above $10^{-3} \Omega^{-1} \mathrm{~cm}^{-1}$ for n-type a-Si:H films and $10^{-4} \Omega^{-1} \mathrm{~cm}^{-1}$ for p-type films. Doped nanocrystalline silicon films deposited above $200{ }^{\circ} \mathrm{C}$ have optimized $\sigma_{\mathrm{d}}$ of 20-100 $\Omega^{-1} \mathrm{~cm}^{-1}$ for n-type and $40 \Omega^{-1} \mathrm{~cm}^{-1}$ for p-type. ${ }^{10}$ A survey of the literature found studies of low $T_{\text {sub }}$ doping from various groups including Beyer and Overhof, ${ }^{11}$ Jang and Kim, ${ }^{12}$ and Roca i Cabarrocas, ${ }^{13}$ for a-Si:H, and Prasad et al., ${ }^{14}$ for nc-Si. In these studies, the $\sigma_{\mathrm{d}}$ were measured in the as-deposited state and then annealed at a temperature higher than the deposition temperature to improve their $\sigma_{\mathrm{d}}$. Table I summarises the results of these studies. An analysis of these results suggests that useful values of $\sigma_{\mathrm{d}}$ can be obtained by $\mathrm{RF}$ at low $T_{\text {sub }}\left(\leq 100{ }^{\circ} \mathrm{C}\right)$ and that $\mathrm{H}_{2}$ dilution is an important parameter determining $\sigma_{\mathrm{d}}$ in these conditions. However, no comprehensive study has so far been performed in this low temperature deposition regime. In this paper, $\mathrm{H}_{2}$ dilution is used to obtain n-type and p-type films, both amorphous and nanocrystalline, at $T_{\text {sub }}=25{ }^{\circ} \mathrm{C}$ and $100{ }^{\circ} \mathrm{C}$, with values of $\sigma_{\mathrm{d}}$ compatible with device applications.

For a systematic study of doping at $T_{\text {sub }}=100{ }^{\circ} \mathrm{C}$ and $25^{\circ} \mathrm{C}$, films were deposited by RF simultaneously on a common plastic, polyethylene terephthalate (PET), and on 
glass, for comparison. The optimized conditions for deposition ${ }^{15}$ of intrinsic films at $100{ }^{\circ} \mathrm{C}$ and $25^{\circ} \mathrm{C}$ were used as starting points for the deposition of the doped films.

\section{Experimental procedures}

\section{Film preparation}

The films were deposited by rf-PECVD in a deposition system described elsewhere. ${ }^{15,16} 1 \%$ dopant gas-to-silane flow rate ratio $\left(F_{\text {dopant }} / F_{\mathrm{SiH}_{4}}\right)$ was used for deposition of amorphous films while $F_{\mathrm{PH}_{3}} / F_{\mathrm{SiH}_{4}}=0.6 \%$ was used for ${ }^{+}{ }^{-n c-S i: H}$ deposition and $F_{\mathrm{B}\left(\mathrm{CH}_{3}\right)_{3}} / F_{\mathrm{SiH}_{4}}=1 \%$ or $F_{\mathrm{B}_{2} \mathrm{H}_{6}} / F_{\mathrm{SiH}_{4}}=0.5 \%$ for $\mathrm{p}^{+}$-nc-Si:H deposition. Hydrogen dilution is defined as $100 \times F_{\mathrm{H}_{2}} /\left(F_{\mathrm{SiH}_{4}}+F_{\mathrm{H}_{2}}\right)$, where $F_{\mathrm{H}_{2}}$ is the hydrogen flow rate and $F_{\mathrm{SiH}_{4}}$ is the silane flow rate.

The inter-electrode distance was $3 \mathrm{~cm}$, the RF power density used was 50 $\mathrm{mW} / \mathrm{cm}^{2}$ for films deposited at $T_{\text {sub }} \geq 100{ }^{\circ} \mathrm{C}$ and $100 \mathrm{~mW} / \mathrm{cm}^{2}$ for films deposited at room temperature, RT. The pressure was 100 mTorr. The thickness of the films was between $\sim 100 \mathrm{~nm}$ and $\sim 300 \mathrm{~nm}$. The sum of the fluxes of the gases was kept constant at around $20 \mathrm{sccm}$, except for the higher hydrogen dilutions where it was necessary to increase the fluxes so that the $\mathrm{SiH}_{4}$ flux was not less than $0.5 \mathrm{sccm}$, which was the lower limit for the silane mass flow controller.

\section{Film characterisation}

Films were deposited simultaneously on two different substrates: Corning 7059 glass and polyethylene terephthalate (PET). Electrical conductivity, Constant 
Photocurrent Measurements (CPM) and Raman spectroscopy were performed on both substrates. Selected films were also deposited on double-side-polished silicon wafers for infrared spectroscopy (IR).

The film thicknesses were measured with a Tencor profilometer. The dark conductivity, $\sigma_{\mathrm{d}}$, was measured between $110^{\circ} \mathrm{C}$ and RT for samples deposited at 100 ${ }^{\circ} \mathrm{C}$ and between $50{ }^{\circ} \mathrm{C}$ and RT for samples deposited at RT to avoid annealing during the measurement. Coplanar Cr contacts, $6 \mathrm{~mm}$ long, $1 \mathrm{~mm}$ apart and approximately $1000 \AA$ thick were used. The activation energy $E_{\mathrm{a}}$ was calculated from $\sigma_{\mathrm{d}}=\sigma_{0} \exp \left[-E_{\mathrm{a}} /\left(k_{\mathrm{B}} T\right)\right]$. CPM was used to measure the sub-band gap absorption, from which the defect density and bandtail slope can be extracted. ${ }^{17}$

Raman spectra were measured in the backscattering geometry using a Raman microprobe. The $514.5 \mathrm{~nm}(2.41 \mathrm{eV})$ laser radiation was obtained from an $\mathrm{Ar}^{+}$laser. The power of the incident beam was set below $50 \mathrm{~mW}$ to avoid thermally induced crystallisation. For nanocrystalline films, the Raman spectrum around the crystalline silicon transverse optical (TO) peak was deconvoluted into its integrated crystalline Gaussian peak, $I_{\mathrm{c}}\left(\sim 520 \mathrm{~cm}^{-1}\right)$, amorphous Gaussian peak, $I_{\mathrm{a}}\left(\sim 480 \mathrm{~cm}^{-1}\right)$, and intermediate Gaussian peak, $I_{\mathrm{m}}\left(\sim 510 \mathrm{~cm}^{-1}\right){ }^{18,19}$ The crystalline fraction, $X_{\mathfrak{c}}$, was calculated from $X_{\mathrm{c}}=\left(I_{\mathrm{c}}+I_{\mathrm{m}}\right) /\left(I_{\mathrm{c}}+I_{\mathrm{m}}+I_{\mathrm{a}}\right) .{ }^{19}$ The crystallite size $d_{\mathrm{c}}$ was calculated from the Scherrer formula ${ }^{20} d_{\mathrm{c}}=k \lambda /\left(B \cos \theta_{\mathrm{B}}\right)$, where, $k \sim 0.9, \lambda$ is the wavelength of the X-ray radiation, $B$ is the FWHM of the peaks (in units of $2 \theta$ ) and $\theta_{\mathrm{B}}$ is the angular position of the peak. 
SIMS analysis was performed by Evans East (East Windsor, NJ) on samples deposited on glass substrates to detect boron (B) and phosphorous (P). Quantification of the profiles was accomplished by analyzing, along with the samples, an ion implanted reference material of $\mathrm{B}$ and $\mathrm{P}$ in crystalline silicon.

\section{Results}

Figure 1 shows the room-temperature dark conductivity, $\sigma_{\mathrm{d}}$ (top), and the activation energy of the dark conductivity, $E_{\mathrm{a}}$ (bottom), of (a) p-type and (b) n-type samples deposited on glass at $T_{\text {sub }}=100{ }^{\circ} \mathrm{C}$ and $25^{\circ} \mathrm{C}$ by rf-PECVD as a function of hydrogen dilution. Also shown, with dotted and dashed lines, are the $\sigma_{\mathrm{d}}$ of intrinsic samples obtained at the same $T_{\text {sub. }}$ In general, the trends in the $\sigma_{\mathrm{d}}$ and $E_{\mathrm{a}}$ of the doped samples as a function of hydrogen dilution mirror those of intrinsic samples with $\sigma_{\mathrm{d}}$ shifted to higher values and $E_{\mathrm{a}}$ to lower values in the doped films. This similarity in behavior can be explained by the observation that the electrical conductivity of both intrinsic and doped samples is dominated by the film structure, i.e., by whether the film is amorphous or nanocrystalline. Table II presents the properties of selected doped films deposited on Corning glass and PET substrates. In general, films deposited on PET showed the same electronic and structural characteristics as those deposited on glass, except when noted.

\section{P-type films}

Figure 1 (a) shows $\sigma_{\mathrm{d}}$ (top) and $E_{\mathrm{a}}$ (bottom) of p-type samples deposited at $T_{\text {sub }}=$ $100{ }^{\circ} \mathrm{C}$ and $T_{\text {sub }}=25{ }^{\circ} \mathrm{C}$ on glass (and at $99 \% \mathrm{H}_{2}$ dilution and $T_{\text {sub }}=25{ }^{\circ} \mathrm{C}$ also on PET) as a function of hydrogen dilution. $\sigma_{\mathrm{d}}$ is $T_{\text {sub }}$ independent in this temperature 
range and is very weakly dependent on hydrogen dilution for hydrogen dilutions below $95 \%$. $\sigma_{\mathrm{d}}$ values for p-type a-Si:H cluster around $2 \times 10^{-7} \Omega^{-1} \mathrm{~cm}^{-1}$ when $\mathrm{B}\left(\mathrm{CH}_{3}\right)_{3}$ is used as the dopant gas and are slightly higher $\left(\sigma_{\mathrm{d}} \sim 6 \times 10^{-7} \Omega^{-1} \mathrm{~cm}^{-1}\right)$ if $\mathrm{B}_{2} \mathrm{H}_{6}$ is used as the source of boron atoms. These values are 1-2 orders of magnitude lower than the $\sigma_{\mathrm{d}}$ of standard p-type a-Si:H films deposited at $T_{\text {sub }} \sim 200-250{ }^{\circ} \mathrm{C} .{ }^{21}$ When the hydrogen dilution is increased, a decrease in $\sigma_{\mathrm{d}}$ prior to crystallization is observed, reaching a minimum $\sigma_{\mathrm{d}}$ at $98-98.5 \% \mathrm{H}_{2}$ dilution. This decrease in $\sigma_{\mathrm{d}}$, also observed in intrinsic films, is attributed to the formation of a highly porous and hydrogen rich material, composed of protocrystallites imbedded in an amorphous tissue, which precedes the nanocrystalline growth regime. ${ }^{22}$ After this minimum, the films deposited at $T_{\text {sub }}=100{ }^{\circ} \mathrm{C}$ show an abrupt increase of $\sigma_{\mathrm{d}}$ upon increasing the $\mathrm{H}_{2}$ dilution $\left(\sigma_{\mathrm{d}}=1.7 \times 10^{-2} \Omega^{-1} \mathrm{~cm}^{-1}\right.$ and $E_{\mathrm{a}}=0.10 \mathrm{eV}$ for the film deposited at $99 \%$ dilution when $\mathrm{B}\left(\mathrm{CH}_{3}\right)_{3}$ is used as dopant gas). This increase corresponds to the formation of a p-type nc-Si:H film (figure 2 (b)). A decrease of crystalline fraction (from $X_{\mathrm{c}}=61 \%$ to $X_{\mathrm{c}}=49 \%$ ) is observed when p-type nc-Si:H film is compared to the corresponding intrinsic film. In the films deposited at $T_{\text {sub }}=25^{\circ} \mathrm{C}$, using $\mathrm{H}_{2}$ dilution $>95 \%$ and $\mathrm{B}\left(\mathrm{CH}_{3}\right)_{3}$ as dopant gas, the $\mathrm{a} \rightarrow \mathrm{nc}$ transition is fully inhibited and the films were not doped.

When $\mathrm{B}_{2} \mathrm{H}_{6}$ is used as the dopant gas, $\sigma_{\mathrm{d}}$ of nc-Si:H samples deposited at $T_{\text {sub }}=$ $100{ }^{\circ} \mathrm{C}$ is increased up to $\sigma_{\mathrm{d}}=1.3 \times 10^{-1} \Omega^{-1} \mathrm{~cm}^{-1}\left(E_{\mathrm{a}}=0.055 \mathrm{eV}\right)$ at $98.5 \% \mathrm{H}_{2}$ dilution and to $\sigma_{\mathrm{d}}=3.9 \times 10^{-1} \Omega^{-1} \mathrm{~cm}^{-1}\left(E_{\mathrm{a}}=0.053 \mathrm{eV}\right)$ at $99 \% \mathrm{H}_{2}$ dilution. The Raman spectrum of p-type films doped from $\mathrm{B}_{2} \mathrm{H}_{6}$ exhibits a $\sim 10 \%$ higher crystalline 
fraction $\left(X_{\mathrm{c}}=58 \%\right)$ than the film deposited using $\mathrm{B}\left(\mathrm{CH}_{3}\right)_{3}$ as dopant gas $\left(X_{\mathrm{c}}=49 \%\right)$ (figure 2 (b)). At $T_{\text {sub }}=25^{\circ} \mathrm{C}$, the Raman spectrum of the film deposited using $99 \%$ $\mathrm{H}_{2}$ dilution (figure 2 (a)) shows an incipient peak near $520 \mathrm{~cm}^{-1}$ but the $\sigma_{\mathrm{d}}$ is still low $\left(\sim 3 \times 10^{-10} \Omega^{-1} \mathrm{~cm}^{-1}\right)$. However, when the same film is deposited on PET, although the Raman-peak shape is similar to that obtained on glass, a significantly higher $\sigma_{\mathrm{d}}=$ $4 \times 10^{-3} \Omega^{-1} \mathrm{~cm}^{-1}$, more typical of doped $\mathrm{nc}-\mathrm{Si}: \mathrm{H}$, is obtained. The higher crystalline fraction could be attributed to the lower level of intrinsic stress present in the films on PET due to the higher compliance of the plastic substrate when compared to glass. A relaxation of the film structure, due to energy transfer through the film-substrate interface as elastic or plastic deformation, at the onset of crystalline growth, could benefit the growth of nc-film on plastic more than on glass, where this effect is minimal.

The boron concentration in p-type amorphous films at both $T_{\text {sub }}=100{ }^{\circ} \mathrm{C}$ and 25 ${ }^{\circ} \mathrm{C}$ was $[\mathrm{B}] \sim 5 \times 10^{20}$ atom $/ \mathrm{cm}^{3}$ for all hydrogen dilutions. [B] decreases to $\sim 7 \times 10^{19}$ atom $/ \mathrm{cm}^{3}$ for nc-Si:H films. The distribution coefficients, ${ }^{8} d_{\mathrm{I}}$, defined as $\left[C_{\mathrm{B}}\right]_{\mathrm{film}} /\left[C_{\mathrm{B}}\right]_{\mathrm{gas}}$ where $\left[C_{\mathrm{B}}\right]_{\mathrm{film}}$ is the boron atomic concentration in the film and $\left[C_{\mathrm{B}}\right]_{\mathrm{gas}}$ is the molecular concentration of the dopant in the plasma, are $\sim 0.8$ for amorphous samples and $d_{\mathrm{I}} \sim 0.1$ for nc-samples.

\section{N-type films}

Figure 1 (b) shows $\sigma_{\mathrm{d}}$ (top) and $E_{\mathrm{a}}$ (bottom) of n-type samples deposited at $T_{\text {sub }}=$ $100^{\circ} \mathrm{C}$ and $T_{\text {sub }}=25^{\circ} \mathrm{C}$ on glass. At $T_{\text {sub }}=100{ }^{\circ} \mathrm{C} \sigma_{\mathrm{d}}$ is $\sim 10^{-3} \Omega^{-1} \mathrm{~cm}^{-1}\left(E_{\mathrm{a}} \sim 0.30 \mathrm{eV}\right)$ for $\mathrm{H}_{2}$ dilution between 90-95\%. As the hydrogen dilution is increased above $95 \%$, 
the conductivity of n-type films decreases at first, paralleling the trend already observed for intrinsic and p-type films. At $T_{\text {sub }}=100^{\circ} \mathrm{C}$, the conductivity of the doped film increases upon further hydrogen dilution $\left(\sigma_{\mathrm{d}}=1.9 \times 10^{-2} \Omega^{-1} \mathrm{~cm}^{-1}\right.$ and $E_{\mathrm{a}}=0.08$ $\mathrm{eV}$ at $98.5 \% \mathrm{H}_{2}$ ). This improved conductivity corresponds to the formation of a nc-Si:H film (figure 2 (b)). The Raman spectrum of this film shows a small crystalline fraction $\left(X_{\mathrm{c}}=26 \%\right)$ when compared to the much stronger peak observed in the corresponding intrinsic film $\left(X_{\mathrm{c}}=61 \%\right.$ ) (figure $2(\mathrm{~b})$ ). At $T_{\text {sub }}=25{ }^{\circ} \mathrm{C}$, the conductivity is never recovered when the hydrogen dilution is increased, because there is no $\mathrm{a} \rightarrow \mathrm{nc}$ transition (figure 2 (a)). The dopant incorporation inhibits crystallization of the films deposited at RT.

At $T_{\text {sub }}=25{ }^{\circ} \mathrm{C}$, amorphous n-type films deposited using $\mathrm{H}_{2}$ dilution below $95 \%$ (and above $\sim 50 \%$ ) have $\sigma_{\mathrm{d}} \sim 1.5 \times 10^{-5} \Omega^{-1} \mathrm{~cm}^{-1}\left(E_{\mathrm{a}} \sim 0.45 \mathrm{eV}\right)$. For depositions using $\mathrm{H}_{2}$ dilution less than $\sim 50 \%$, silicon powders form in the plasma and deposit on the substrate producing a non-homogeneous film that has poor adhesion to the substrate.

The composition of n-type films deposited by rf-PECVD is $T_{\text {sub }}$ independent, in the range of $T_{\text {sub }}$ studied. The phosphorous incorporation in amorphous films is [P] > $10^{21}$ atom $/ \mathrm{cm}^{3}$. [P] decreases to $\sim 3 \times 10^{20}$ atoms $/ \mathrm{cm}^{3}$ as the $\mathrm{H}_{2}$ dilution is increased beyond $95 \%$. $d_{\mathrm{I}}$ is $\sim 3$ in amorphous samples decreasing to $d_{\mathrm{I}} \sim 1$ in nc-material. 


\section{Discussion}

\section{Low- $T_{\text {sub }}$ doping versus standard high- $T_{\text {sub }}$ doping}

Doped nanocrystalline silicon deposited by rf-PECVD at low $T_{\text {sub }}$ show (1) lower $\sigma_{\mathrm{d}}$ by several orders of magnitude; (2) smaller grain size (of the order of 3-4 nm) and (3) lower crystalline fraction when compared with optimized films grown at $T_{\text {sub }} \sim$ $200-250{ }^{\circ} \mathrm{C}$. A summary of the measured properties of these films is presented in table II. The reduced mobility of precursors on the growing film surface during low substrate temperature deposition results in films with lower crystalline fraction and smaller grain size ${ }^{23}$ which in turn limits the carrier mobility and, as a consequence, the conductivity in the film. Higher values of $\sigma_{\mathrm{d}}$ are obtained for p-type nc-Si:H films (using $\mathrm{B}_{2} \mathrm{H}_{6}$ ) than for n-type films at both $T_{\text {sub }}=25^{\circ} \mathrm{C}$ and $T_{\text {sub }}=100{ }^{\circ} \mathrm{C}$ due mainly to the higher crystalline fraction measured in the films doped from $\mathrm{B}_{2} \mathrm{H}_{6}$ (figure 2).

$\mathrm{N}$-type a-Si:H films deposited at $100{ }^{\circ} \mathrm{C}$ have structural and transport properties $\left(\sigma_{\mathrm{d}} \sim 10^{-3} \Omega^{-1} \mathrm{~cm}^{-1}\right)$ closer to high- $T_{\text {sub }}$ films $\left(T_{\text {sub }}=250^{\circ} \mathrm{C}, \sigma_{\mathrm{d}} \sim 3 \times 10^{-2} \Omega^{-1} \mathrm{~cm}^{-1}\right)$. At $T_{\text {sub }}=25^{\circ} \mathrm{C}$ the properties of the films degrade and the conductivity of n-type a-Si:H is $\sim 10^{-5} \Omega^{-1} \mathrm{~cm}^{-1}$. P-type a-Si:H films deposited at $T_{\text {sub }}=100{ }^{\circ} \mathrm{C}$ and $25{ }^{\circ} \mathrm{C}$ show similar $\sigma_{\mathrm{d}}\left(\sim 5 \times 10^{-7} \Omega^{-1} \mathrm{~cm}^{-1}\right)$ which are lower than that of optimized $\mathrm{p}^{+} \mathrm{a}-\mathrm{Si}: \mathrm{H}$ films deposited at $T_{\text {sub }}=250{ }^{\circ} \mathrm{C}\left(\sigma_{\mathrm{d}} \sim 5 \times 10^{-6} \Omega^{-1} \mathrm{~cm}^{-1}\right)$ (see table II).

\section{The control of defect density with $\mathrm{H}_{2}$ dilution}

In device-quality amorphous silicon, the presence of hydrogen is needed to stabilize its structure by breaking weak bonds and passivating dangling bonds. ${ }^{24}$ 
Reduced hydrogen diffusion at the surface and in the bulk of films deposited at substrate temperatures below $150{ }^{\circ} \mathrm{C}$ results in a structure which is kinetically limited and consequently, highly defective. ${ }^{25}$ The use of hydrogen dilution of silane has been shown to improve the structural and electronic properties of a-Si:H deposited at these low temperatures. ${ }^{15,23}$ In the case of doping, the results of the previous sections show that the most conductive p-type and n-type a-Si:H samples are also obtained with $\mathrm{H}_{2}$ dilution of the reactant gases. Figure 3 shows the $\sigma_{d}$ of doped a-Si:H films plotted as a function of the defect density, measured by CPM, of intrinsic films deposited using the same hydrogen dilution and other experimental conditions as the corresponding doped films. The figure shows that the doping efficiency correlates with the deposition conditions which yield intrinsic films with lower subgap defect density. This correlation is stronger in the case of n-type films than in the case of p-type ones.

It is possible to estimate the conductivity one should expect to obtain from a certain doping level by making the following assumptions: (1) assume that $\sim 1 \%$ of the dopant concentration in the solid is in the four-fold configuration and that $\sim 10 \%$ of the donor electrons reside in the bandtail states, thus for $[\mathrm{P}] \sim 10^{20} \mathrm{~cm}^{-3}, \mathrm{n}_{\mathrm{bt}} \sim 10^{17}$ $\mathrm{cm}^{-3}$ and (2) the drift mobility, $\mu_{\mathrm{d}}$, of electrons in a-Si:H is $\sim 1 \mathrm{~cm}^{2} \mathrm{~V}^{-1} \mathrm{~s}^{-1}$. This gives an estimated conductivity of $\sigma_{\mathrm{d}}=e \mu_{\mathrm{d}} n_{\mathrm{bt}} \sim 10^{-2} \Omega^{-1} \mathrm{~cm}^{-1}$ for standard n-type RF a-Si:H prepared above the equilibration temperature ${ }^{8}$ when the dopant concentration in the film is $[\mathrm{P}] \sim 10^{20} \mathrm{~cm}^{-3}$. For p-type a-Si:H, deposited above the equilibration temperature, a value of $\sigma_{\mathrm{d}}=e \mu_{\mathrm{d}} n_{\mathrm{bt}} \sim 10^{-5} \Omega^{-1} \mathrm{~cm}^{-1}$ is expected since $\mu_{\mathrm{d}} \sim 10^{-3} \mathrm{~cm}^{2} \mathrm{~V}^{-1} \mathrm{~s}^{-1}$ [ref.8]. These estimated values are in good agreement with the conductivities obtained in doped a-Si:H when $T_{\text {sub }}>200{ }^{\circ} \mathrm{C}$ (see table II). For films deposited at lower 
substrate temperatures, the defect density increases (see figure 3). These defects act to compensate the dopants, decreasing the doping efficiency for films deposited at lower $T_{\text {sub. }}$ The beneficial role of atomic hydrogen in $\mathrm{H}_{2}$-assisted deposition of doped films is most likely related to the passivation of dangling bonds, paralleling the case for intrinsic a-Si:H films, rather than to the activation of the donor or acceptor atoms. In fact, as will be discussed in next section, the reactivity of hydrogen with phosphorous and, especially, with boron in the doped films leads to the passivation of donors and acceptors, respectively.

\section{Dopant activation in a-Si:H and nc-Si:H films}

Results of isochronal annealing of selected films deposited at low $T_{\text {sub }}$ are presented in figure 4 (p-type) and figure 5 (n-type). Samples were annealed for one hour at each temperature. The temperature increment was $50{ }^{\circ} \mathrm{C}$, starting at $100{ }^{\circ} \mathrm{C}$ and ending at $300{ }^{\circ} \mathrm{C}$. The dark conductivity of the samples was measured after each annealing step.

A comparison of figures 4 and 5 shows that n-type and p-type films respond differently to the annealing treatments. For nanocrystalline silicon, $\sigma_{\mathrm{d}}$ of $\mathrm{p}$-type films deposited at $T_{\text {sub }}=100{ }^{\circ} \mathrm{C}$ shows no significant change upon annealing, indicating that the dopants were already fully activated in the as-deposited state. However, for n-type nc-Si:H film deposited at $100{ }^{\circ} \mathrm{C}$ its $\sigma_{\mathrm{d}}$ improved from $2.5 \times 10^{-2} \Omega^{-1} \mathrm{~cm}^{-1}$ to $5 \times$ $10^{-1} \Omega^{-1} \mathrm{~cm}^{-1}$ upon annealing at $300^{\circ} \mathrm{C}$. Since this film has a high amorphous fraction $\left(X_{\mathrm{c}}=37 \%\right.$, figure 2) it is possible that the observed increase in $\sigma_{\mathrm{d}}$ is mainly a consequence of defect annealing in the grain boundaries. 
For amorphous films, the p-type samples (figure 4) improved upon annealing, reaching $\sigma_{\mathrm{d}} \sim 10^{-4} \Omega^{-1} \mathrm{~cm}^{-1}$ at $300^{\circ} \mathrm{C}$, which is comparable to the $\sigma_{\mathrm{d}}$ of p-type a-Si:H deposited at $T_{\text {sub }} \sim 250-300{ }^{\circ} \mathrm{C}$. However, in the n-type case (figure 5), only the film deposited at $T_{\text {sub }}=25^{\circ} \mathrm{C}$ showed an increase in $\sigma_{\mathrm{d}}$ upon annealing. The fact that the ntype sample deposited at $T_{\text {sub }}=100{ }^{\circ} \mathrm{C}$ showed no increase in $\sigma_{\mathrm{d}}$ is consistent with the explanation that the deposition temperature was already near the equilibration temperature of the phosphorous doped a-Si:H structure which is thought to be $\sim 100$ ${ }^{\circ} \mathrm{C}$ [ref.8]. Annealing can induce two different transformations that explain the increase in the $\sigma_{\mathrm{d}}$ of a-Si:H films: (1) the number of impurity atoms that adopt the 4fold configuration of the host, and thus become active donors or acceptors, may increase; (2) annealing of the native intrinsic defects can also increase the doping efficiency.

The largest increase in the value of $\sigma_{\mathrm{d}}$ of doped a-Si:H films upon annealing is observed in p-type films (figure 5). This behavior is coherent with the formation, in the as-deposited state, of boron-hydrogen complexes $^{26}$ that are stable until temperatures above $100{ }^{\circ} \mathrm{C}$. The B-H complexes have been identified by IR spectroscopy $^{27,28}$ and by Raman spectroscopy ${ }^{29}$ in boron-implanted crystalline silicon followed by a hydrogenation step. The observed IR band, centered at $\sim 1900 \mathrm{~cm}^{-1}$, is interpreted as a $\mathrm{Si}-\mathrm{H}$ stretching vibration modified by the presence of the neighboring boron atom connected to a different $\mathrm{Si}$, which reduces the force constant of the $\mathrm{Si}-\mathrm{H}$ bond by means of a three-body force involving the bridging $\mathrm{Si}-\mathrm{H}-\mathrm{B}$ atoms. ${ }^{27}$ However, the attempts made in the present work to identify this bond using normal 
incidence IR transmission spectroscopy were not successful. The hydrogen content measured by IR in intrinsic films deposited using the same $\mathrm{H}_{2}$ dilution and similar deposition conditions to those that were used for doping was $\sim 20$ atom $\%$ for $T_{\text {sub }}=$ $100{ }^{\circ} \mathrm{C}$ and $\sim 25$ atom $\%$ for $T_{\text {sub }}=25^{\circ} \mathrm{C}$ [ref.15]. In the doped films, due to the high concentration of $\mathrm{Si}-\mathrm{H}$ bonds in the films and a low boron concentration $(\sim 0.1$ atom $\%$ ), the weak B-H peak around $1900 \mathrm{~cm}-1$ is probably buried in the strong absorption band centered around $2000 \mathrm{~cm}-1$ that is due to the 'normal' Si-H stretching vibrations. When the annealing temperature increases, the weak B-H bonds are broken, as the hydrogen mobility increases in the silicon network, and a growing quantity of Batoms, no longer stabilized by the hydrogen in the 3 -fold configuration, adopt an active 4-fold configuration that increases the doping efficiency.

The phosphorous-hydrogen complexes that form ${ }^{30}$ in n-type a-Si:H are much less stable than the B-H ones and are fully dissociated above $\sim 60{ }^{\circ} \mathrm{C}$. In agreement with this observation, the n-type a-Si:H film deposited at $T_{\text {sub }}=100{ }^{\circ} \mathrm{C}$ showed no significant change upon annealing, while the film deposited at $T_{\text {sub }}=25^{\circ} \mathrm{C}$ showed a larger increase in $\sigma_{\mathrm{d}}$, from $\sigma_{\mathrm{d}}=1.7 \times 10^{-5} \Omega^{-1} \mathrm{~cm}^{-1}$ to $\sigma_{\mathrm{d}}=1.6 \times 10^{-4} \Omega^{-1} \mathrm{~cm}^{-1}$.

In order to assess the relative contribution of both processes - dopant activation and defect annealing - intrinsic films deposited using the same $T_{\text {sub }}$ and $\mathrm{H}_{2}$ dilution and otherwise similar deposition conditions to those used in the doped films, were annealed at $200{ }^{\circ} \mathrm{C}$ for one hour. The defect density, measured by CPM, decreased from $2.2 \times 10^{16} \mathrm{~cm}^{-3}$ before annealing to $1.2 \times 10^{16} \mathrm{~cm}^{-3}$ after annealing for the film deposited at $T_{\text {sub }}=100{ }^{\circ} \mathrm{C}$ and from $5.5 \times 10^{16} \mathrm{~cm}^{-3}$ to $4.7 \times 10^{16} \mathrm{~cm}^{-3}$ for the film 
deposited at $T_{\text {sub }}=25^{\circ} \mathrm{C}$. These defect densities are much smaller than the dopantinduced defects in the doped films and their variation upon annealing is not expected to significantly change the carrier concentration in these films. Dark conductivity $\left(\sigma_{d}\right.$ $<10^{-13} \Omega^{-1} \mathrm{~cm}^{-1}$ and $\sigma_{\mathrm{d}}=2.1 \times 10^{-13} \Omega^{-1} \mathrm{~cm}^{-1}$ for the films deposited at $T_{\text {sub }}=25^{\circ} \mathrm{C}$ and $100{ }^{\circ} \mathrm{C}$, respectively) and photoconductivity, $\sigma_{\mathrm{ph}}\left(\sigma_{\mathrm{ph}}=1.3 \times 10^{-6} \Omega^{-1} \mathrm{~cm}^{-1}\right.$ and $\sigma_{\mathrm{ph}}=$ $4.7 \times 10^{-6} \Omega^{-1} \mathrm{~cm}^{-1}$ at $T_{\text {sub }}=25^{\circ} \mathrm{C}$ and $100{ }^{\circ} \mathrm{C}$, respectively) of the intrinsic films showed only relatively small changes and $\sigma_{\mathrm{ph}}$ did not approach the higher values $\left(\sigma_{\mathrm{ph}} \sim 10^{-4} \Omega^{-1} \mathrm{~cm}^{-1}\right)$ characteristic of intrinsic a-Si:H films deposited by RF at the annealing temperature, $T_{\text {sub }} \sim 200^{\circ} \mathrm{C}$.

These results lead to the conclusion that dopant activation is the dominant mechanism responsible for the large increase in $\sigma_{d}$ of the p-type films upon annealing. In the case of the much smaller improvement observed in the $\sigma_{d}$ of n-type a-Si:H films deposited at $25^{\circ} \mathrm{C}$ both processes - dopant activation and defect annealing could have comparable importance.

\section{Crystallinity of low- $T_{\text {sub }}$ doped films}

Dopant incorporation possibly causes high levels of distortion in the small host crystallites thus reducing the tendency towards crystallization. This effect is reflected in the following observations: (1) the crystalline fraction in doped films is always smaller than that obtained for intrinsic films prepared at the same $T_{\text {sub }}$ using the same hydrogen dilution (figure 2 and table II); (2) the crystallite size is reduced with respect to the intrinsic films (table II); and (3) the a $\rightarrow$ nc transition in n-type films requires higher values of $\mathrm{H}_{2}$ dilution than for intrinsic material (figure 1). This effect is more 
pronounced in doping with $\mathrm{PH}_{3}$ where films deposited at room temperature were amorphous as measured by Raman, even at very high $\mathrm{H}_{2}$ dilutions $(99 \%) . \mathrm{B}_{2} \mathrm{H}_{6}$ had a smaller effect than $\mathrm{B}\left(\mathrm{CH}_{3}\right)_{3}$ as an inhibitor of crystalline growth, possibly due to the smaller size of its molecule and to the absence of the carbon atom which could also hinder crystallization. However, even in the films doped with $\mathrm{B}_{2} \mathrm{H}_{6}$, the crystalline fraction was always smaller than in corresponding intrinsic nanocrystalline films (figure 2).

\section{Conclusions}

If one sets a lower limit for $\sigma_{\mathrm{d}}$ of doped a-Si:H $\left(\sigma_{\mathrm{d}}=10^{-6} \Omega^{-1} \mathrm{~cm}^{-1}\right)$ and nc-Si:H $\left(\sigma_{\mathrm{d}}=10^{-2} \Omega^{-1} \mathrm{~cm}^{-1}\right)$ films to be considered acceptable as contact layers in thin-film devices, then it is possible to assess the viability of doping at low- $T_{\text {sub. }} \mathrm{N}$-type a-Si:H with $\sigma_{\mathrm{d}} \geq 10^{-6} \Omega^{-1} \mathrm{~cm}^{-1}$ can be deposited at $T_{\text {sub }}=100^{\circ} \mathrm{C}$ and $25^{\circ} \mathrm{C}$. P-type doping of aSi:H was achieved with $\sigma_{\mathrm{d}} \sim 10^{-6} \Omega^{-1} \mathrm{~cm}^{-1}$ at $T_{\text {sub }}=100{ }^{\circ} \mathrm{C}$ and $25{ }^{\circ} \mathrm{C}\left(90 \% \mathrm{H}_{2}\right.$ dilution). N-type and p-type doping of nc-Si:H was achieved at $100^{\circ} \mathrm{C}$. At $25^{\circ} \mathrm{C}$, only p-type doping of nc-Si:H was successful, using diborane as the doping gas on PET substrates. Doping conductivity is lowered at low substrate temperatures in the amorphous films, because of the formation of hydrogen-dopant atom complexes and of the higher defect density, and, in the nanocrystalline films, because the addition of dopant gases to the gas mixture during deposition decreases the crystalline fraction and the crystallite size.

Within the limitations described above, it can be concluded that it is possible to prepare adequately doped contact layers for device applications at $T_{\text {sub }} \leq 100{ }^{\circ} \mathrm{C}$ on 
glass and plastic substrates by rf-PECVD.

\section{Acknowledgements}

The authors thank Nuno Louro for help with the annealing measurements and Rui Almeida (IST/INESC) for the use of the Raman equipment. This work was supported by the Fundação para a Ciência e Tecnologia (FCT) through Pluriannual Contracts with UCES/ICEMS (IST) and INESC and by projects in the Praxis and POCTI programs. One of the authors (P.A.) thanks the Department of Physics of the University of Minho for a leave of absence. 


\section{References}

* Present address: Department of Physics, University of Minho, Campus de Azurem, 4800-058 Guimarães, Portugal. Electronic mail: palpuim@ fisica.uminho.pt

${ }^{1}$ V. Lumelsky, M. S. Shur and S. Wagner, IEEE Sensors J. 1, 41 (2001).

${ }^{2}$ S. M. Gates, in Mater. Res. Soc. Symp. Proc., vol. 467, edited by S. Wagner, M. Hack, E. Schiff, R. Schropp and I. Shimizu (Materials Research Society, Pittsburgh, Pennsylvania, 1997) pp. 843-849.

${ }^{3}$ H. Gleskova, S. Wagner, Z. Suo, in Mater. Res. Soc. Symp. Proc., Vol. 508, edited by G. N. Parsons, C. C. Tsai, T. S. Fahlen, and C.H. Seager (Materials Research Society, Pittsburgh, Pennsylvania, 1998), pp. 73-78.

${ }^{4}$ J. P. Conde, P. Alpuim and V. Chu, in Mater. Res. Soc. Symp. Proc., Vol. 715, edited by J.R. Abelson, J.B. Boyce, J.D. Cohen, H. Matsumura and J. Robertson (Materials Research Society, Pittsburgh, Pennsylvania, 2002), pp. A3.1.1- A3.1.6.

${ }^{5}$ C.-S. Yang, L. L. Smith, C. B. Arthur and G. N. Parsons, J. Vac. Sci. Technol. B 18 (2), 683 (2000).

${ }^{6}$ M. S. Feng, C. W. Liang and D. Tseng, J. Electrochem. Soc. 141, 1040 (1994).

${ }^{7}$ C. S. McCormick, C. E. Weber and J. R. Abelson, J.Vac. Sci. Technol. A 15(5), 2770 (1997).

${ }^{8}$ R. A. Street, Hydrogenated Amorphous Silicon (Cambridge University Press, Cambridge, 1991), pp. 27, 139, 210, 238. 
${ }^{9}$ W. E. Spear, P. G. LeComber, Philos. Mag. 33, 935 (1976).

${ }^{10}$ G. Willeke, in Amorphous \& Microcrystalline Semiconductor Devices, edited by J. Kanicki, (Artech House, Inc., Norwood, Massachussets, 1992), Vol. II, pp.5588.

${ }^{11}$ W. Beyer and H. Overhof, in Semiconductors and Semimetals, edited by J. I. Pankove (Academic Press, New York, 1984), Vol. 21, Part C, chapter 8, p.288.

12 J. Jang and S. C. Kim, J. Appl. Phys. 61, 2092 (1987).

${ }^{13}$ P. Roca i Cabarrocas, Appl. Phys. Lett. 65, 1674 (1994).

${ }^{14}$ K. Prasad, F. Finger, S. Dubail, A. Shah and M. Schubert, J. Non-Cryst. Solids, 137-138, 681 (1991).

${ }^{15}$ P. Alpuim, V. Chu and J. P. Conde, J. Appl. Phys. 86, 3812 (1999).

${ }^{16}$ P. Alpuim, V. Chu and J. P. Conde, in Mater. Res. Soc. Symp. Proc., Vol. 609, edited by H. Branz, R. Collins, S. Guha, H. Okamoto and M. Stutzmann (Materials Research Society, Pittsburgh, Pennsylvania, 2000), p. A22.6.1.

${ }^{17}$ M. Vanacek, J. Kocka, J. Strichlik, Z. Kosicek, O. Stika and A. Triska, Sol. Energy Mater. 8, 411 (1983).

${ }^{18}$ S. Veprek, F. A. Sarott and Z. Iqbal, Phys. Rev.B 36, 3344 (1987).

${ }^{19}$ T. Kaneko, M. Wakagi, K. Onisawa and T. Minemura, Appl. Phys. Lett. 64, 1865 (1994). 
${ }^{20}$ E. Findeisen, R. Feidenhans'1, M. E. Vigild, K. N. Clausen, J. B. Hansen, M. D. Bentzon and J. P. Goff, J. Appl. Phys. 76, 4636 (1994).

${ }^{21}$ R. A. Street, in Mat. Res. Soc. Bull., 17, 70, 1992.

${ }^{22}$ P. Roca i Cabarrocas, in Mater. Res. Soc. Symp. Proc., Vol. 507, edited by R.

Schropp, H. Branz, M. Hack, I. Shimizu and S. Wagner (Materials Research Society, Pittsburgh, Pennsylvania, 1998), p. 855.

${ }^{23}$ M. Yamaguchi and K. Morigaki, Philos. Mag. B 79, 387 (1999).

${ }^{24}$ R. A. Street, Phys. Rev. B 43, 2454 (1991).

${ }^{25}$ R. A. Street, Phys. Rev. B 44, 10610 (1991).

${ }^{26}$ P. St'ahel, P. Roca i Cabarrocas, P. Sladek and M. L. Theye, in Mater. Res. Soc. Symp. Proc., Vol. 507, edited by R. Schropp, H. Branz, M. Hack, I. Shimizu and S. Wagner (Materials Research Society, Pittsburgh, Pennsylvania, 1998), pp. 649-654.

${ }^{27}$ J. I. Pankove, P. J. Zanzucchi and C. W. Magee, G. Lucovsky, Appl. Phys. Lett. 46, 421 (1985).

${ }^{28}$ M. Stavola, S. J. Pearton, J. Lopata and W. C. Dautremont-Smith, Phys. Rev. B 37, 8313 (1988).

${ }^{29}$ M. Stutzmann, Phys. Rev. B 35, 5921 (1987).

${ }^{30}$ N. M. Johnson, C. Herring and D. J. Chadi, Phys. Rev. Lett. 56, 769 (1986). 
Table I. Summary of low temperature doping results from literature

\begin{tabular}{cccccccc}
\hline $\begin{array}{c}T_{\text {sub }} \\
\left({ }^{\circ} \mathrm{C}\right)\end{array}$ & Film & \multicolumn{2}{c}{$\begin{array}{c}\sigma_{\mathrm{d}}(\text { as deposited }) \\
\left(\Omega^{-1} \mathrm{~cm}^{-1}\right)\end{array}$} & $\begin{array}{c}T_{\text {anneal }} \\
\left({ }^{\circ} \mathrm{C}\right)\end{array}$ & $\begin{array}{r}\sigma_{\mathrm{d}}(\text { annealed }) \\
\left(\Omega^{-1} \mathrm{~cm}^{-1}\right)\end{array}$ & Reference \\
& & n-type & p-type & & n-type & p-type & \\
\hline RT & a-Si:H & $10^{-8}$ & $10^{-6}$ & 300 & $10^{-2}$ & $10^{-4}$ & 10 \\
100 & a-Si:H & $10^{-7}$ & $10^{-6}$ & 300 & $10^{-2}$ & $10^{-4}$ & 10 \\
$50-90$ & a-Si:H & - & $10^{-7}$ & 300 & - & $10^{-4}$ & 11 \\
50 & a-Si:H & $5 \times 10^{-8}$ & $5 \times 10^{-5}$ & 200 & $10^{-5}$ & $10^{-3}$ & 12 \\
30 & a-Si:H & $10^{-6}$ & - & 200 & $10^{-4}$ & & 13 \\
30 & nc-Si & $10^{-2}$ & - & & & & 13 \\
70 & nc-Si & 1 & - & 200 & $\sim 10$ & & 13 \\
\hline \hline
\end{tabular}


Table II. Properties of selected n-type and p-type a-Si:H and nc-Si:H samples

\begin{tabular}{|c|c|c|c|c|c|c|c|c|c|c|c|c|}
\hline $\begin{array}{l}T_{\text {sub }} \\
\left({ }^{\circ} \mathrm{C}\right)\end{array}$ & Sample & $\begin{array}{c}\mathrm{H}_{2} \text { dil. } \\
(\%)\end{array}$ & $\begin{array}{c}\text { dopant } \\
\text { gas }\end{array}$ & $\begin{array}{l}\frac{F_{\text {dopant }}}{F_{\mathrm{SiH}_{4}}} \\
\times 100 \% \\
\end{array}$ & $\begin{array}{c}{[\mathrm{P}] \text { or }[\mathrm{B}]} \\
\text { from SIMS } \\
\left(\mathrm{atm} \cdot \mathrm{cm}^{-3}\right)\end{array}$ & $\begin{array}{c}X_{\mathrm{c}}^{\text {Raman }} \\
(\%) \\
\text { on glass }\end{array}$ & $\begin{array}{c}X_{\mathrm{c}}^{\text {Raman } \dagger} \\
(\%) \\
\text { on PET }\end{array}$ & $\begin{array}{c}\sigma_{\mathrm{d}} \\
\left(\Omega^{-1} \mathrm{~cm}^{-1}\right) \\
\text { on glass }\end{array}$ & $\begin{array}{c}\sigma_{\mathrm{d}}^{\dagger} \\
\left(\Omega^{-1} \mathrm{~cm}^{-1}\right) \\
\text { on PET }\end{array}$ & $\begin{array}{c}E_{\mathrm{a}, \mathrm{d}} \\
(\mathrm{eV}) \\
\text { on glass }\end{array}$ & $\begin{array}{c}E_{\mathrm{a}, \mathrm{d}}^{\dagger} \\
(\mathrm{eV}) \\
\text { on PET }\end{array}$ & $\begin{array}{c}d_{\mathrm{c}} \\
(\mathrm{nm}) \\
\text { on glass }\end{array}$ \\
\hline 25 & N1575 & 90 & $\mathrm{PH}_{3}$ & $1 \%$ & $1.4 \times 10^{21}$ & amorph. & amorph. & $1.7 \times 10^{-5}$ & $1.2 \times 10^{-5}$ & 0.450 & 0.486 & - \\
\hline 25 & P1571 & 90 & $\mathrm{~B}\left(\mathrm{CH}_{3}\right)_{3}$ & $1 \%$ & $6.0 \times 10^{19}$ & amorph. & amorph. & $1.8 \times 10^{-7}$ & $3.6 \times 10^{-7}$ & 0.580 & 0.540 & - \\
\hline 25 & P1696 & 90 & $\mathrm{~B}_{2} \mathrm{H}_{6}$ & $1 \%$ & - & amorph. & amorph. & $6.0 \times 10^{-7}$ & $1.1 \times 10^{-6}$ & 0.620 & 0.570 & - \\
\hline 25 & P1709 & 99 & $\mathrm{~B}_{2} \mathrm{H}_{6}$ & $0.5 \%$ & $1.9 \times 10^{20}$ & 23 & 28 & $2.6 \times 10^{-10}$ & $4.0 \times 10^{-3}$ & 0.795 & 0.076 & 3.0 \\
\hline 100 & N1581 & 95 & $\mathrm{PH}_{3}$ & $1 \%$ & $1.3 \times 10^{21}$ & amorph. & amorph. & $2.0 \times 10^{-3}$ & $9.9 \times 10^{-4}$ & 0.313 & 0.337 & - \\
\hline 100 & N1580 & 98.5 & $\mathrm{PH}_{3}$ & $0.6 \%$ & $3.4 \times 10^{20}$ & 37 & 75 & $1.9 \times 10^{-2}$ & $1.4 \times 10^{-2}$ & 0.100 & 0.085 & 3.3 \\
\hline 100 & P1597 & 90 & $\mathrm{~B}\left(\mathrm{CH}_{3}\right)_{3}$ & $1 \%$ & $4.4 \times 10^{20}$ & amorph. & amorph. & $1.5 \times 10^{-7}$ & $1.4 \times 10^{-7}$ & 0.620 & 0.647 & - \\
\hline 100 & P1681 & 90 & $\mathrm{~B}_{2} \mathrm{H}_{6}$ & $1 \%$ & - & amorph. & amorph. & $4.0 \times 10^{-7}$ & $5.9 \times 10^{-7}$ & 0.650 & 0.623 & - \\
\hline 100 & P1600 & 99 & $\mathrm{~B}\left(\mathrm{CH}_{3}\right)_{3}$ & $1 \%$ & $7.0 \times 10^{19}$ & 49 & 68 & $1.7 \times 10^{-2}$ & $1.3 \times 10^{-2}$ & 0.100 & 0.085 & 4.0 \\
\hline 100 & P1700 & 99 & $\mathrm{~B}_{2} \mathrm{H}_{6}$ & $0.5 \%$ & - & 58 & 54 & $3.9 \times 10^{-1}$ & $2.9 \times 10^{-1}$ & 0.053 & 0.054 & 3.5 \\
\hline 250 & N1727 & 90 & $\mathrm{PH}_{3}$ & $1 \%$ & $9.5 \times 10^{20}$ & amorph. & - & $2.5 \times 10^{-2}$ & - & 0.217 & - & - \\
\hline 250 & N1726 & 98,5 & $\mathrm{PH}_{3}$ & $0.6 \%$ & $1.9 \times 10^{20}$ & 81 & - & 22 & - & 0.025 & - & \\
\hline 200 & P182 & 33 & $\mathrm{~B}\left(\mathrm{CH}_{3}\right)_{3}$ & $1 \%$ & - & amorph. & - & $5.6 \times 10^{-6}$ & - & 0.530 & - & - \\
\hline 250 & $\mathrm{P} 1712$ & 99 & $\mathrm{~B}\left(\mathrm{CH}_{3}\right)_{3}$ & $1 \%$ & $2.5 \times 10^{19}$ & 83 & - & $6.5 \times 10^{-2}$ & - & 0.065 & - & \\
\hline
\end{tabular}

${ }^{\dagger}$ Property measured on film deposited on polyethylene terephthalate (PET) substrate. (1) Dopant gas was $\mathrm{B}\left(\mathrm{CH}_{3}\right)$ 



\section{Figure captions}

Figure 1. $\sigma_{d}$ (top) and $E_{a}$ (bottom) of p-type ((a), open symbols) and n-type ((b), solid symbols) films deposited by $\mathrm{RF}$ at $T_{\text {sub }}=100{ }^{\circ} \mathrm{C}(\Delta, \square, \boldsymbol{\square})$ and at $T_{\text {sub }}=25^{\circ} \mathrm{C}$ $(\nabla, \circ, \bullet)$ on glass substrates (except where noted) as a function of hydrogen dilution. For p-type films, the triangles refer to doping with diborane while the other symbols refer to doping with trimethylboron. Also shown are the $\sigma_{\mathrm{d}}$ of intrinsic samples obtained at $T_{\text {sub }}=25^{\circ} \mathrm{C}$ (dots) and $T_{\text {sub }}=100{ }^{\circ} \mathrm{C}$ (short dashes).

Figure 2. Raman spectra of n-type and p-type films deposited by RF at (a) $T_{\text {sub }}=$ $25^{\circ} \mathrm{C}$ and (b) $T_{\text {sub }}=100{ }^{\circ} \mathrm{C}$ using high $\mathrm{H}_{2}$ dilution on glass substrates. Also shown are spectra of intrinsic nanocrystalline films deposited at the same $T_{\text {sub }}$ using comparable $\mathrm{H}_{2}$ dilutions.

Figure 3. $\sigma_{\mathrm{d}}$ of n-type and p-type a-Si:H deposited at $T_{\text {sub }}=25^{\circ} \mathrm{C}, 100{ }^{\circ} \mathrm{C}$ and 250 ${ }^{\circ} \mathrm{C}$ as a function of the dangling bond concentration, $N_{\mathrm{D}}$, measured by CPM, in the corresponding intrinsic film (deposited using the same $T_{\text {sub }}$ and $\mathrm{H}_{2}$ dilution).

Figure 4. $\sigma_{\mathrm{d}}$ of p-type a-Si:H and nc-Si:H films as-deposited, after 6 months at room temperature and after five annealing steps of one hour at increasing annealing temperature.

Figure 5. $\sigma_{\mathrm{d}}$ of n-type a-Si:H and nc-Si:H films as-deposited, after 6 months at room temperature and after five annealing steps of one hour at increasing annealing temperature. 
Figure 1, P. Alpuim, Journal of Vacuum Science and Technology A

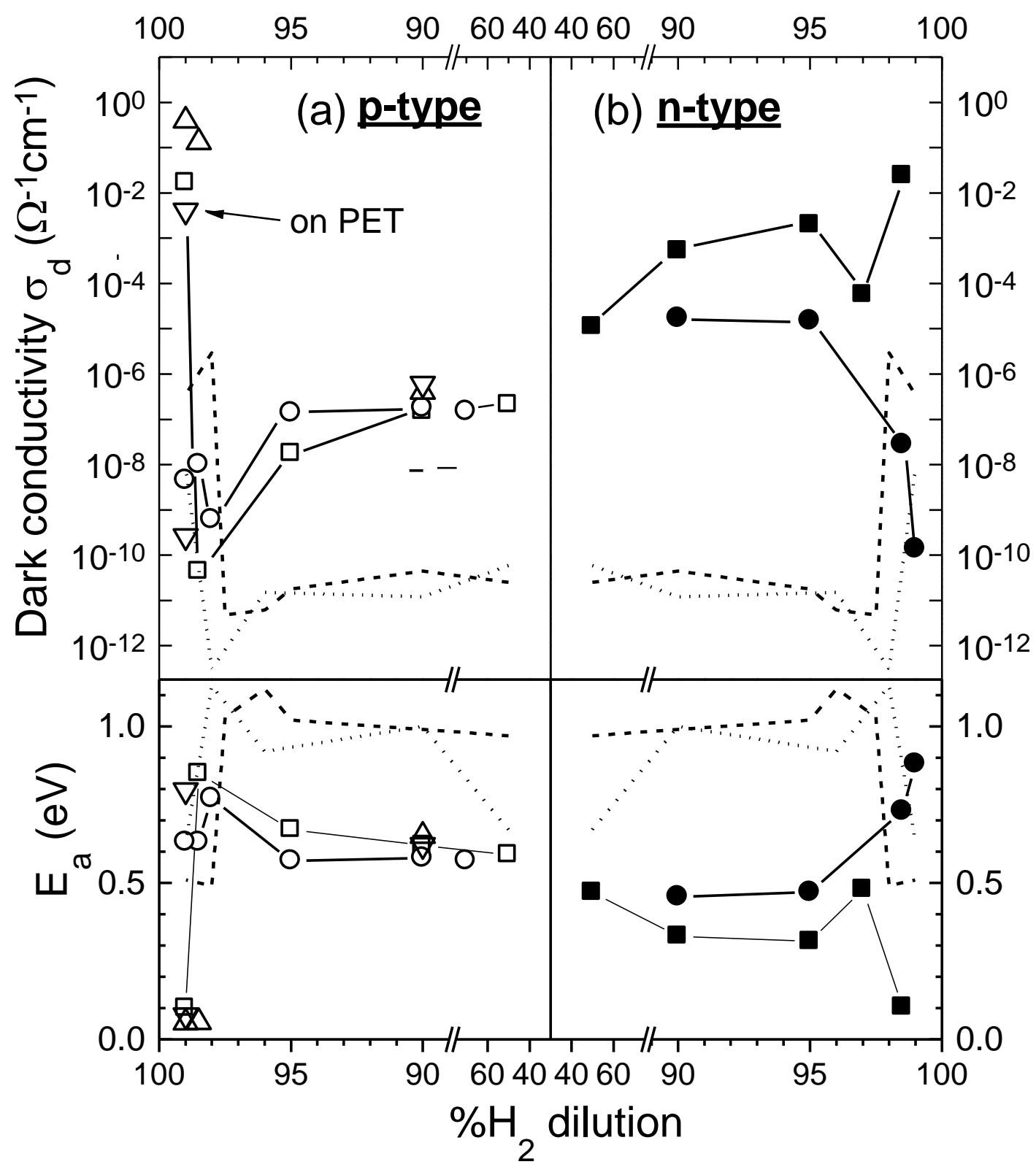


Figure 2, P. Alpuim, Journal of Vacuum Science and Technology A

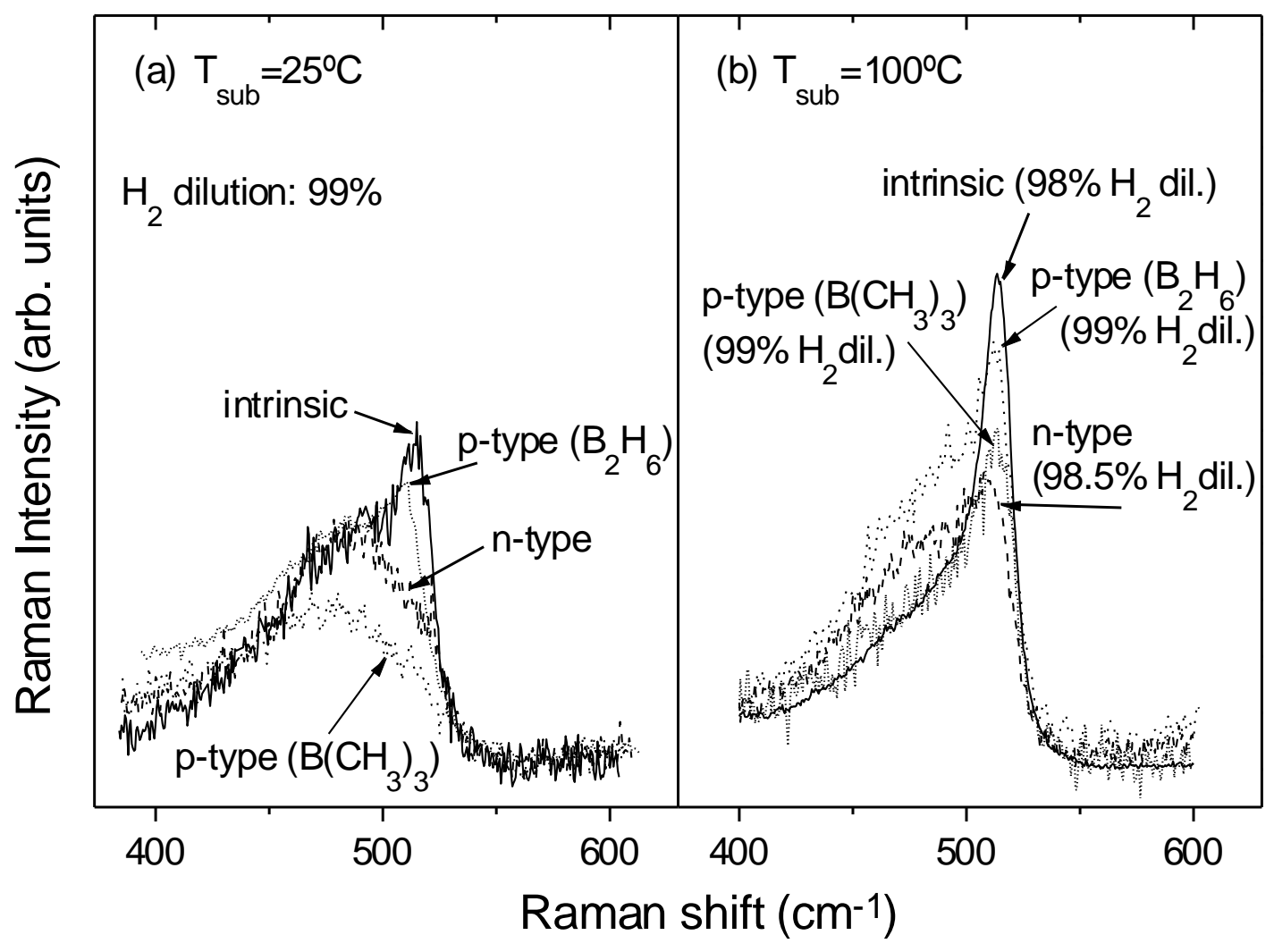


Figure 3, P. Alpuim, Journal of Vacuum Science and Technology A

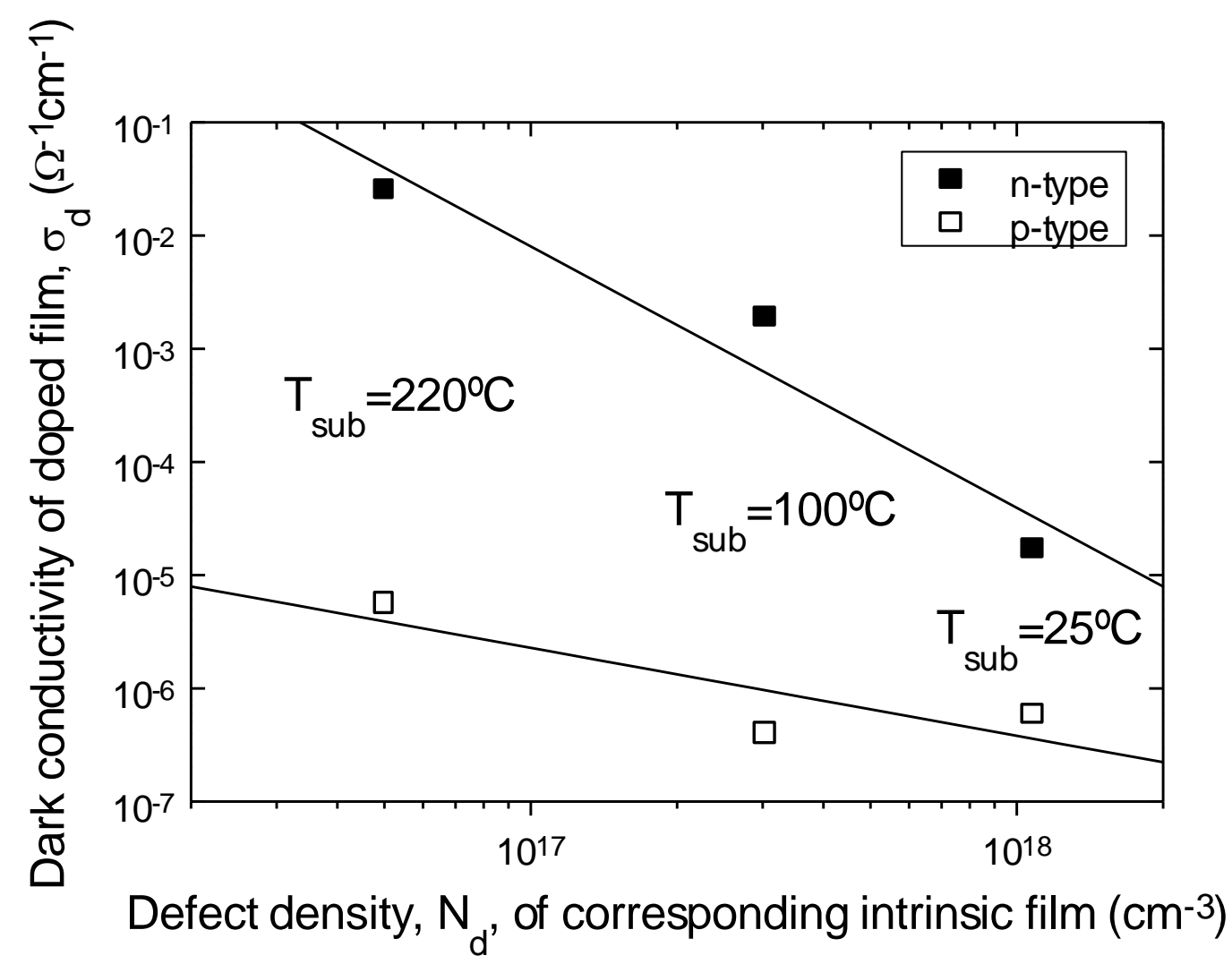


Figure 4, P. Alpuim, Journal of Vacuum Science and Technology A

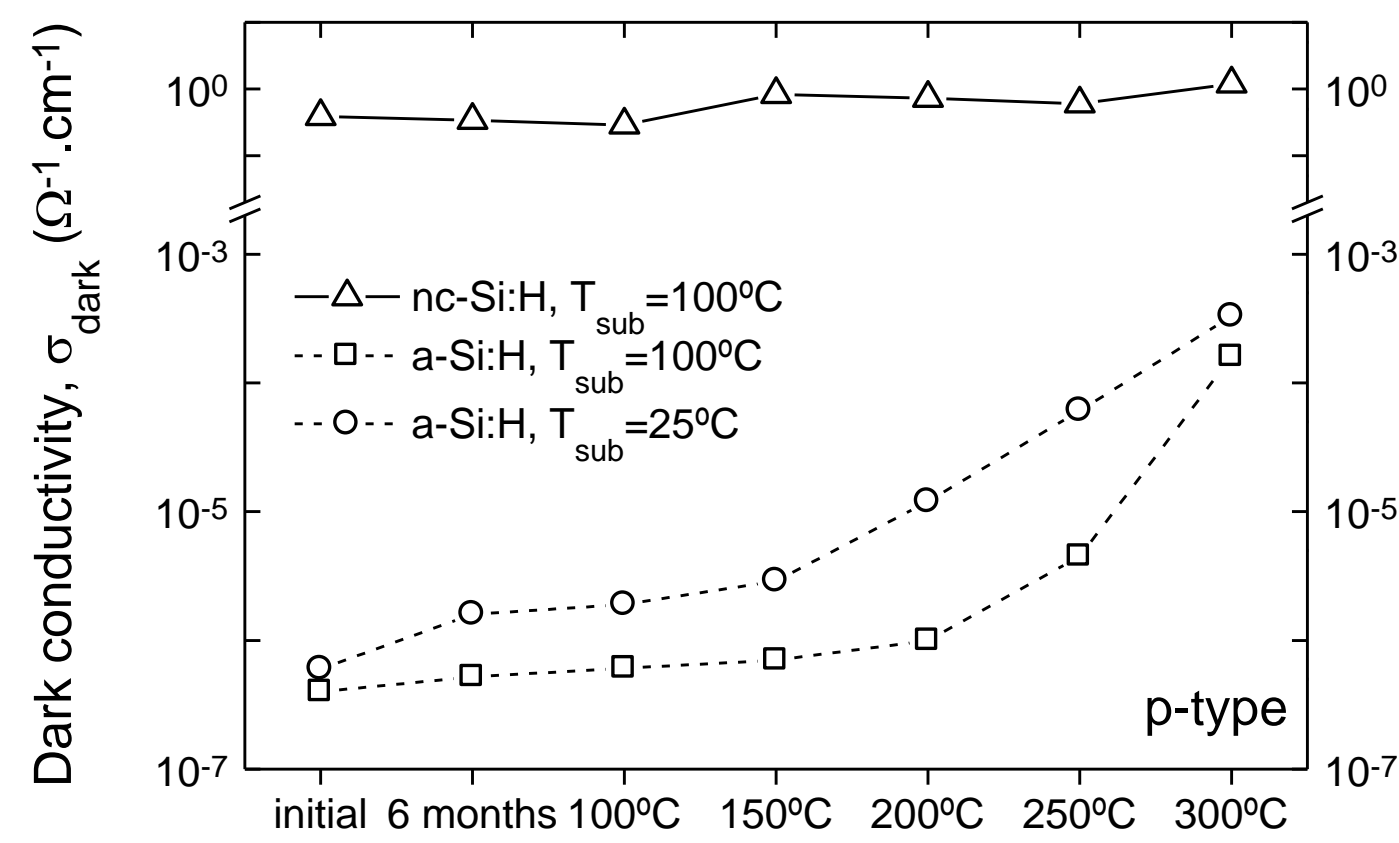

Annealing temperature 
Figure 5, P. Alpuim, Journal of Vacuum Science and Technology A

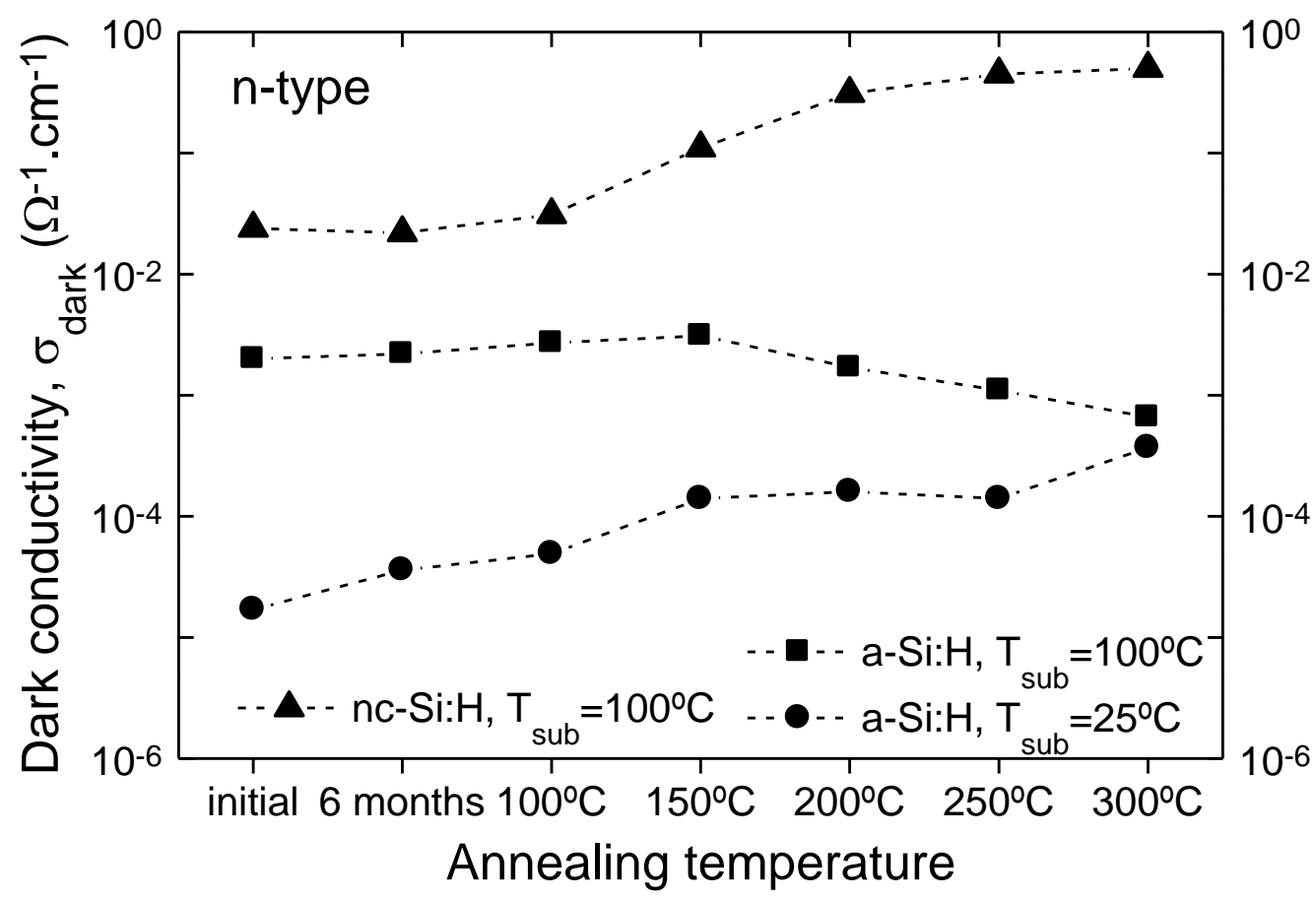

